\title{
Development of new microsatellite markers and their application in the analysis of genetic diversity in lentils
}

\author{
Aladdin Hamwieh"), Sripada M. Udupa ${ }^{2}$, Ashutosh Sarker'), Christian Jung ${ }^{3)}$ and Michael Baum*1) \\ 1) International Center for Agricultural Research in the Dry Areas (ICARDA), P.O. Box 5466, Aleppo, Syria \\ 2) ICARDA-INRA Cooperative Research Project, International Center for Agricultural Research in the Dry Areas (ICARDA), B.P. 6299, \\ Rabat, Morocco \\ 3) Plant Breeding Institute, Christian-Albrechts University Kiel, Olshausen Str. 40, D-24098, Germany
}

This paper reports the development of new microsatellite markers for lentil (Lens culinaris subsp. culinaris) and their use for genetic diversity analysis of a lentil core collection developed at ICARDA (Aleppo-Syria). Fourteen new markers were developed from microsatellite flanking sequences of a genomic library from a cultivated lentil accession ILL5588. The core collection used comprises 109 accessions from 15 countries representing 57 cultigens (including 18 breeding lines) from 8 countries and 52 wild types of germplasm (L. culinaris subsp. orientalis, L. culinaris subsp. tomentosus and L. culinaris subsp. odemensis) from 11 countries. Total number of alleles detected across all microsatellite loci was 182, with a mean of 13 alleles per locus. The wild accessions were rich in alleles (151 alleles) compared to cultigens (114 alleles). The genetic diversity index for the microsatellite loci in the wild accessions ranged from 0.16 (for locus SSR28 in L. culinaris subsp. odemensis) to 0.93 (for locus SSR66 in L. culinaris subsp. orientalis) with a mean of 0.66 , while in the cultigens genetic diversity varied between 0.03 (locus SSR28) and 0.87 (locus SSR207) with a mean of 0.65 . The cluster analysis indicated two major clusters, mainly one with the cultigens and the other with the wild accessions.

Key Words: lentil, Lens, microsatellite, biodiversity.

\section{Introduction}

Lentil (Lens culinaris Medik. subsp. culinaris) is an annual self-pollinated diploid ( $2 x=2 n=14$ chromosomes) species, and a highly valued food legume grown extensively in over 35 countries situated in South Asia, Middle East, North Africa, North America and Australia. Worldwide lentil production in 2007 was 3.78 million ton (Mt) from an area of 3.8 million ha., with an average productivity $1019.1 \mathrm{~kg} / \mathrm{ha}$ (FAOSTAT, 2008). Currently, India leads the world in lentil production and consumption, and Canada and Turkey are the world's largest lentil exporters. Lentil seed has a broad range of uses for human consumption (in soups, stews, salads and vegetarian dishes) and its plant parts, excluding seeds, are used as animal feed around the world, and the different seed and plant types adapted to an increasingly wide range of ecologies.

Lentil originated in the Fertile Crescent of the Near East and later spread to North Africa and eastern Ethiopia, central and southern Europe, North America, Oceania and South Asia (Duke 1981). It is the oldest of the domesticated grain legumes (Bahl et al. 1993). In addition to cultivated lentil,

Communicated by Donghe Xu

Received June 30, 2008. Accepted January 22, 2009.

*Corresponding author (e-mail: m.baum@cgiar.org) the genus Lens consists of four wild species: L. culinaris, L. ervoides, L. lamottei and L. nigricans (van Oss et al. 1997). The species Lens culinaris Medikus has three wild subspecies: L. culinaris subsp. orientalis, L. culinaris subsp. odemensis and L. culinaris subsp. tomentosus (Ferguson et al. 2000); among these, L. culinaris subsp. orientalis is considered to be the progenitor of the cultivated lentil. All these species and subspecies are mostly distributed in the Mediterranean region (Ladizinsky et al. 1984). The wild gene pool constitutes a large reservoir of genetic diversity, and contains several potential traits for genetic improvement of lentils (Sarker and Erskine 2006).

Genetic diversity and the relationships among different species of Lens are of great importance for lentil's genetic resources conservation and breeding potential. Molecular marker studies have made significant contributions to our understanding of genetic diversity and relatedness in various crops (Struss and Plieske 1998, Udupa et al. 1999, Abe et al. 2003). The main benefit of using molecular markers over morphological markers is that they are good indicators of genetic distances and diversity among accessions because of their selective neutrality (Winter and Kahl 1995).

Over the years, several studies have assessed genetic diversity and phylogenetic relationships in the genus Lens using protein and DNA markers. Isozymes, RFLPs, RAPDs and AFLP have all been used in genetic diversity and 
phylogenetic analyses in the Lens genus. Analysis of seed protein polymorphism showed close relationships between the subspecies culinaris and orientalis in comparison with the other wild species (Hoffman et al. 1986). Restriction fragment length polymorphism (RFLP) markers were used to study diversity and phylogenies among different species (Havey and Muehlbauer 1989). Furthermore, random amplified polymorphic DNA (RAPD) and amplified fragment length polymorphism (AFLP) analyses have provided similar conclusions regarding the phylogeny of Lens (Abo-elwafa et al. 1995, Sharma et al. 1995, Sharma et al. 1996). However, AFLP analysis detected a higher level of polymorphism than did the RAPD analysis (Collard et al. 2005).

Microsatellite markers have been successfully employed in many crops for genetic diversity studies and are useful for a variety of applications in plant genetics and breeding including genetic diversity studies. This is because of their high degree of polymorphism, multiallelic nature, reproducibility, codominant inheritance, relative abundance and good genome coverage (Powell et al. 1996). Recently Hamwieh et al. (2005) developed microsatellite markers for lentil and used 30 of them to construct the genetic map. In this study, we developed an additional set of 14 microsatellite markers for lentil and used them to estimate genetic diversity and relationships within a core collection of lentil germplasm held at ICARDA.

\section{Material and Methods}

\section{Plant material}

A core collection of lentil germplasm held at ICARDA was developed by selecting a small set of accessions representing the diversity of the entire collection, based on passport and morphological data. This collection consists of 57 L. culinaris subsp. culinaris (cultivated lentil), 30 L. culinaris Medik. subsp. orientalis, 18 L. culinaris Medik. subsp. odemensis, and four L. culinaris subsp. tomentosus accessions. These accessions originated from 15 countries, and 18 ICARDA breeding lines were used for this study (Table 1).

\section{DNA extraction}

Total DNA was extracted according to the CTABmethod, described by Rogers and Bendich (1985) with minor modifications. The fresh leaf material was collected from a single seedling of each accession.

\section{Isolation of microsatellites}

A genomic library of cultivated lentil (ILL 5588) was constructed and approximately 200,000 colonies were screened for six synthetic repeats, namely $(\mathrm{GT})_{10},(\mathrm{GA})_{10}$, $(\mathrm{GC})_{10},(\mathrm{GAA})_{8},(\mathrm{TA})_{10}$, and (TAA $)_{5}$ as described previously by Hamwieh et al. (2005). The microsatellite motifs were classified as 'simple' and 'compound' as well as 'perfect' and 'imperfect' repeats as described previously (Weber 1990, Hüttel et al. 1999, Sibly et al. 2001). A microsatellite is referred as 'simple', if a single type of repeat unit repeats several times (e.g., (CA) $)_{n}$ (TAA $)_{k}$; etc.). On the other hand, a 'compound' microsatellite consists of stretches of more than one type of repeat unit (e.g., $(\mathrm{GA})_{n} \cdot(\mathrm{TA})_{k}$; $(\mathrm{GT})_{k} \cdot(\mathrm{TAA})_{l} \cdot$ (TA $)_{m}$, etc.). A 'perfect' microsatellite means that the microsatellite sequence does not contain mutations or interruptions (e.g., $(\mathrm{CA})_{n}$; (TAA $)_{k} ;(\mathrm{CT})_{m} \cdot(\mathrm{GAA})_{n}$, etc.). An 'imperfect' microsatellite means that the microsatellite sequence does contain mutations or interruptions (e.g. $(\mathrm{CA})_{n} \mathrm{CC}(\mathrm{CA})_{m} ;(\mathrm{TA})_{k} \mathrm{AA}(\mathrm{TA})_{l} \cdot(\mathrm{GA})_{m}$, etc.). In the above examples, subscripts $k, l, n$ and $m$ denote number of times the particular microsatellite motif repeats.

\section{Primer design and PCR amplification of microsatellites}

Primer pairs were designed close to the microsatellite repeats in the flanking regions as described by Hamwieh et al. (2005). PCR amplification reactions of microsatellites were performed in a final volume of $20 \mu \mathrm{l}$ in the presence of $10 \mathrm{ng}$ of template DNA, $10 \mathrm{pmol}$ of each primer, $0.2 \mathrm{mM}$ of each deoxynucleotide, $1 \times$ PCR buffer (Invitrogen, Carlsbad, CA), and 1 unit Taq polymerase (Invitrogen). The forward primer was 5'-labeled with one of three fluorophores (6FAM, NED, or TET). PCR was carried out using a PE 9600 thermocycler (Perkin-Elmer, Foster City, CA). After 3 min at $94^{\circ} \mathrm{C}, 30 \mathrm{cy}-$ cles were performed with $30 \mathrm{~s}$ at $94^{\circ} \mathrm{C}, 30 \mathrm{~s}$ at either $52^{\circ} \mathrm{C}$, $53^{\circ} \mathrm{C}, 54^{\circ} \mathrm{C}$ or $55^{\circ} \mathrm{C}$ (depending on the locus, Table 2 ), and 1 min at $72^{\circ} \mathrm{C}$, followed by final extension step of $5 \mathrm{~min}$ at $72^{\circ} \mathrm{C}$. Amplified products were detected on a MegaBACE 500 Capillary System (Amersham Pharmacia Biotech, Piscataway, NJ). Samples were prepared by adding $1 \mu \mathrm{l}$ of diluted PCR products to $9 \mu$ formamide and samples included 1\% (v/v) ET-Rox 900 bp DNA size standard (Amersham Bioscience). Microsatellite fragment sizes were estimated using the MegaBACE Genetic Profiler Version 2.0 (Amersham Pharmacia Biotech).

\section{Data analysis}

Analyses of microsatellite diversity were conducted at the locus level in a given species. For each locus, we estimated the number of alleles, range of fragment sizes, mean of fragment size and genetic diversity (Nei 1973) using PowerMarker V3.25 (Liu and Muse 2005). Power markers allowed to group the data at several categories or levels. The genetic relationships were further estimated at the levels of accession, subspecies, and countries. The unweighted pairgroup method arithmetic average (UPGMA) was used to cluster 109 accessions and neighbor-joining (NJ) methods to cluster the groups at subspecies and countries level. The cluster analysis and bootstrap analysis (with 100 bootstrap samples) were performed using PAST software version 1.62 (Hammer et al. 2001). The Principal Coordinate Analysis (PCA) was performed according to Davis (1986) using the PAST software. 
Table 1. A core collection of lentil germplasm held at ICARDA

\begin{tabular}{|c|c|c|c|c|c|}
\hline Accession No. & Origin & L. culinaris subsp. & Accession No. & Origin & L. culinaris subsp. \\
\hline ILL5888 & Bangladesh & culinaris & ILWL21 & Palestine & odemensis \\
\hline ILL8006 & Bangladesh & culinaris & ILWL153 & Syria & odemensis \\
\hline ILL8007 & Bangladesh & culinaris & ILWL164 & Syria & odemensis \\
\hline ILL10005 & ICARDA & culinaris & ILWL172 & Syria & odemensis \\
\hline ILL10011 & ICARDA & culinaris & ILWL173 & Syria & odemensis \\
\hline ILL10012 & ICARDA & culinaris & ILWL174 & Syria & odemensis \\
\hline ILL8076 & ICARDA & culinaris & ILWL175 & Syria & odemensis \\
\hline ILL8174 & ICARDA & culinaris & ILWL202 & Turkey & odemensis \\
\hline ILL88527 & ICARDA & culinaris & ILWL235 & Syria & odemensis \\
\hline ILL9830 & ICARDA & culinaris & ILWL238 & Syria & odemensis \\
\hline ILL9832 & ICARDA & culinaris & ILWL322 & Syria & odemensis \\
\hline ILL9837 & ICARDA & culinaris & ILWL356 & Syria & odemensis \\
\hline ILL9896 & ICARDA & culinaris & ILWL357 & Syria & odemensis \\
\hline ILL9899 & ICARDA & culinaris & ILWL362 & Syria & odemensis \\
\hline ILL9907 & ICARDA & culinaris & ILWL363 & Syria & odemensis \\
\hline ILL9918 & ICARDA & culinaris & ILWL404 & Syria & odemensis \\
\hline ILL9922 & ICARDA & culinaris & ILWL438 & Turkey & odemensis \\
\hline ILL9924 & ICARDA & culinaris & ILWL449 & Turkey & odemensis \\
\hline ILL9936 & ICARDA & culinaris & ILWL4 & Turkey & orientalis \\
\hline ILL9986 & ICARDA & culinaris & ILWL490 & Armenia & orientalis \\
\hline ILL9995 & ICARDA & culinaris & ILWL6 & Turkey & orientalis \\
\hline ILL2501 & India & culinaris & ILWL7 & Turkey & orientalis \\
\hline ILL2565 & India & culinaris & ILWL11 & Syria & orientalis \\
\hline ILL2580 & India & culinaris & ILWL71 & Iran & orientalis \\
\hline ILL2684 & India & culinaris & ILWL72 & Cyprus & orientalis \\
\hline ILL3596 & India & culinaris & ILWL74 & Palestine & orientalis \\
\hline ILL3614 & India & culinaris & ILWL81 & Turkey & orientalis \\
\hline ILL7556 & India & culinaris & ILWL118 & Syria & orientalis \\
\hline ILL7558 & India & culinaris & ILWL145 & Syria & orientalis \\
\hline ILL7715 & India & culinaris & ILWL200 & Turkey & orientalis \\
\hline ILL7716 & India & culinaris & ILWL214 & Iran & orientalis \\
\hline ILL8008 & India & culinaris & ILWL215 & Iran & orientalis \\
\hline L-4147 & India & culinaris & ILWL220 & Turkey & orientalis \\
\hline ILL759 & Iran & culinaris & ILWL228 & Syria & orientalis \\
\hline ILL5244 & Jordan & culinaris & ILWL229 & Syria & orientalis \\
\hline ILL5883 & Jordan & culinaris & ILWL230 & Syria & orientalis \\
\hline ILL7162 & Pakistan & culinaris & ILWL231 & Syria & orientalis \\
\hline ILL7163 & Pakistan & culinaris & ILWL326 & Cyprus & orientalis \\
\hline ILL7164 & Pakistan & culinaris & ILWL341 & Jordan & orientalis \\
\hline ILL8112 & Pakistan & culinaris & ILWL344 & Syria & orientalis \\
\hline ILL8114 & Pakistan & culinaris & ILWL345 & Syria & orientalis \\
\hline ILL91517 & Pakistan & culinaris & ILWL346 & Syria & orientalis \\
\hline ILL7723 & Pakistan & culinaris & ILWL372 & Uzbekistan & orientalis \\
\hline ILL4400 & Syria & culinaris & ILWL373 & Uzbekistan & orientalis \\
\hline ILL4401 & Syria & culinaris & ILWL374 & Uzbekistan & orientalis \\
\hline ILL5597 & Syria & culinaris & ILWL376 & Tajikistan & orientalis \\
\hline ILL780 & Syria & culinaris & ILWL378 & Turkmenistan & orientalis \\
\hline ILL1878 & Turkey & culinaris & ILWL402 & Lebanon & orientalis \\
\hline ILL1880 & Turkey & culinaris & ILWL90 & Turkey & tomentosus \\
\hline ILL7155 & Turkey & culinaris & ILWL91 & Turkey & tomentosus \\
\hline ILL8143 & Turkey & culinaris & ILWL307 & Turkey & tomentosus \\
\hline ILL8146 & Turkey & culinaris & ILWL308 & Turkey & tomentosus \\
\hline ILL8611 & Turkey & culinaris & & & \\
\hline ILL8612 & Turkey & culinaris & & & \\
\hline AKM-302 & Turkey & culinaris & & & \\
\hline ILL632 & Turkey & culinaris & & & \\
\hline ILL323 & Serbia \& Montenegro & culinaris & & & \\
\hline
\end{tabular}


Table 2. Forward and reverse primer sequences and annealing temperature used for amplification of 14 microsatellite loci

\begin{tabular}{|c|c|c|c|c|c|}
\hline Primers & Forward sequence & Reverse sequence & $\begin{array}{c}\text { Temperature } \\
\left({ }^{\circ} \mathrm{C}\right)\end{array}$ & $\begin{array}{l}\text { Expected size } \\
\text { (bp) }\end{array}$ & Microsatellite motif \\
\hline SSR 28 & GAGGGCATAAATTCAGATTC & GGACAACGCACATTTGATG & 53 & 383 & $(\mathrm{TG})_{15}$ \\
\hline SSR 34-2 & CGGCGGATGAAACTAAAG & CATTTCСТTCACAАACCAAC & 53 & 185 & $(\mathrm{GT})_{22}$ \\
\hline SSR $46-2$ & CACTAAACATGGAAAATAGG & CTTATCTTTGTTTGAAGCAA & 50 & 157 & $(\mathrm{CA})_{8}$ \\
\hline SSR 66 & GGTAGTGGTGAGGAATGAC & GCATCACTGCAACAGACC & 55 & 253 & $(\mathrm{TG})_{10}(\mathrm{AG})_{18}$ \\
\hline SSR 72 & CAAACAGTACAAGGAAAGGAG & CTGACTGAGCTGCTTGAAC & 55 & 253 & $(\mathrm{AAG})_{9}$ \\
\hline SSR 90 & CCGTGTACACCCCTAC & CGTCTTAAAGAGAGTGACAC & 55 & 181 & $(\mathrm{TG})_{11}(\mathrm{AG})_{10}$ \\
\hline SSR 132RN & CCAGAACAAACGTAAACC & CTATCGCATATGAGTGAAC & 52 & 330 & $(\mathrm{GT})_{9}$ \\
\hline SSR 183 & GCTCGCATTGGTGAAAC & CATATATAGCAGACCGTG & 52 & 119 & $(\mathrm{AC})_{8}$ \\
\hline SSR 191 & GCAAATTTCTTGGTCTACAC & GGGCACAGATTCATAAGG & 53 & 238 & $(\mathrm{AC})_{17}(\mathrm{AT})_{13}$ \\
\hline SSR 197 & CACCAATCACCAACACAC & GAGCTGTGAAGTCTTATCTG & 54 & 173 & $(\mathrm{TA})_{13}$ \\
\hline SSR 202 & САACСТCАСТTАССТТАС & GCTCTTTATCATCATTCTAC & 52 & 220 & $(\mathrm{CA})_{8}(\mathrm{CCA})_{6}(\mathrm{CA})_{5}$ \\
\hline SSR 207 & GAGAGATACGTCAGAGTAG & GATTGTGCTTCGGTGGTTC & 55 & 227 & $(\mathrm{CA})_{22}$ \\
\hline SSR 230 & CCAACAACAATTCACCATAC & AACATTGTACTGAGAGGTG & 53 & 251 & $(\mathrm{CA})_{28}(\mathrm{TA})_{8}$ \\
\hline SSR 253 & GAAGAAGCATTCACGGTG & GAGGGACTACTATATCAG & 53 & 139 & $(\mathrm{AC})_{8}$ \\
\hline
\end{tabular}

\section{Results}

\section{Isolation of microsatellites}

The screening of around 200,000 genomic clones for $(\mathrm{GT})_{10},(\mathrm{GA})_{10},(\mathrm{GC})_{10},(\mathrm{GAA})_{8},(\mathrm{TA})_{10}$, and $(\mathrm{TAA})_{5}$ sequences, resulted 371 clones expected to have the microsatellite. These 371 clones were confirmed as 'positive clones' after two rounds of hybridization using $(\mathrm{GT})_{10}$, $(\mathrm{GA})_{10},(\mathrm{GC})_{10},(\mathrm{TA})_{10},(\mathrm{TAA})_{5}$ and $(\mathrm{GAA})_{8}$ as probes. Of these, only 243 clones were sequenced, while the other clones were not sequenced either because of small insert or because of suspected duplicates. The clones were sequenced in either one direction (only 23 clones) or both directions (220 clones sequenced). Upon comparing sequences, we observed that $71.2 \%$ of the repeat sequences were simple sequence repeats (SSRs). Among the SSR motifs, dinucleotide repeats were more common than other types with GT/CA repeats at a frequency of $33.1 \%$, followed by TA/AT repeats at $10.2 \%$. Among the trinucleotide repeats, TAA/ATT motifs were most predominant at a frequency of $3.4 \%$ (Table 3 ). From this sequence information, more than 170 primer pairs were designed and used for amplification of the corresponding microsatellite using DNA from the donor line ILL 5588. Out of the 170 primer pairs, 58 pairs (34\%) amplified monomorphic fragments and 56 pairs $(33 \%)$ produced PCR products with polymorphism. The remaining pairs produced either smear or nonspecific amplifications.

Out of 56 polymorphic microsatellite primer pairs (loci), 30 have been previously used to construct a linkage map in lentil (Hamwieh et al. 2005). For the present study, 26 polymorphic microsatellite loci for which sequences are not yet published were used. Of these, 12 produced many polymorphic amplicons which were not close to the expected size in ILL 5588 and therefore eliminated from this study. The remaining 14 microsatellite primers which yielded amplicons close to the expected sizes were selected to profile the genetic diversity in the core collection. Nine of these loci
Table 3. Microsatellite motifs observed in the lentil genomic library

\begin{tabular}{|c|c|c|c|c|}
\hline Type* & & Microsatellite motif & Number & $\%$ Occurrence \\
\hline \multirow[t]{16}{*}{ Simple } & \multirow[t]{8}{*}{ Perfect } & $\mathrm{CA} / \mathrm{GT}$ & 57 & 24.2 \\
\hline & & $\mathrm{CG} / \mathrm{GC}$ & 2 & 0.8 \\
\hline & & CT/GA & 7 & 3.0 \\
\hline & & CTT/GAA & 3 & 1.3 \\
\hline & & AT/TA & 21 & 8.9 \\
\hline & & ATT/TAA & 7 & 3.0 \\
\hline & & Others types & 37 & 15.7 \\
\hline & & Total & 134 & 56.8 \\
\hline & \multirow[t]{8}{*}{ Imperfect } & $\mathrm{CA} / \mathrm{GT}$ & 21 & 8.9 \\
\hline & & $\mathrm{CG} / \mathrm{GC}$ & 0 & 0.0 \\
\hline & & CT/GA & 1 & 0.4 \\
\hline & & CTT/GAA & 0 & 0.0 \\
\hline & & $\mathrm{AT} / \mathrm{TA}$ & 3 & 1.3 \\
\hline & & ATT/TAA & 1 & 0.4 \\
\hline & & Others types & 8 & 3.4 \\
\hline & & Total & 34 & 14.4 \\
\hline \multirow[t]{3}{*}{ Compound } & Perfect & & 38 & 16.1 \\
\hline & Imperfect & & 30 & 12.7 \\
\hline & Total & & 68 & 28.8 \\
\hline Total & & & 236 & 100 \\
\hline
\end{tabular}

* The microsatellite motifs were classified as simple and compound repeats as well as perfect and imperfect repeats as described previously (Weber 1990, Hüttel et al. 1999, Sibly et al. 2001).

contained simple and perfect repeats and the other five contained compound microsatellites repeats.

\section{Variation at microsatellite loci in cultivated and wild lentil subspecies}

All of the primer pairs tested amplified fragments in wild relatives with the PCR program developed for cultivated subspecies; this indicates the conservation of microsatellite primers in related subspecies. Both inter- and intra-specific differences in amplified fragments were found for all the 
Table 4. Variation at microsatellite loci in four sub-species of Lens culinaris

\begin{tabular}{|c|c|c|c|c|c|c|c|c|}
\hline \multirow[b]{2}{*}{ Locus } & \multicolumn{2}{|c|}{ culinaris } & \multicolumn{2}{|c|}{ orientalis } & \multicolumn{2}{|c|}{ tomentosus } & \multicolumn{2}{|c|}{ odemensis } \\
\hline & $\begin{array}{l}\text { No. of } \\
\text { alleles }\end{array}$ & $\begin{array}{l}\text { Genetic } \\
\text { diversity }\end{array}$ & $\begin{array}{l}\text { No. of } \\
\text { alleles }\end{array}$ & $\begin{array}{l}\text { Genetic } \\
\text { diversity }\end{array}$ & $\begin{array}{l}\text { No. of } \\
\text { alleles }\end{array}$ & $\begin{array}{l}\text { Genetic } \\
\text { diversity }\end{array}$ & $\begin{array}{l}\text { No. of } \\
\text { alleles }\end{array}$ & $\begin{array}{c}\text { Genetic } \\
\text { diversity }\end{array}$ \\
\hline SSR66 & 14 & 0.84 & 19 & 0.93 & 6 & 0.81 & 12 & 0.88 \\
\hline SSR28 & 2 & 0.03 & 5 & 0.29 & 2 & 0.22 & 3 & 0.16 \\
\hline SSR34-2 & 9 & 0.67 & 6 & 0.76 & 3 & 0.62 & 6 & 0.62 \\
\hline SSR46-2 & 5 & 0.68 & 5 & 0.71 & 3 & 0.53 & 4 & 0.54 \\
\hline SSR72 & 5 & 0.63 & 5 & 0.76 & 3 & 0.59 & 5 & 0.77 \\
\hline SSR90 & 11 & 0.74 & 12 & 0.80 & 3 & 0.66 & 6 & 0.71 \\
\hline SSR132RN & 8 & 0.66 & 11 & 0.86 & 4 & 0.66 & 8 & 0.59 \\
\hline SSR183 & 6 & 0.64 & 8 & 0.77 & 3 & 0.63 & 8 & 0.76 \\
\hline SSR191 & 13 & 0.80 & 13 & 0.88 & 5 & 0.78 & 12 & 0.83 \\
\hline SSR197 & 14 & 0.75 & 16 & 0.89 & 4 & 0.56 & 12 & 0.85 \\
\hline SSR202 & 4 & 0.26 & 2 & 0.22 & 2 & 0.38 & 4 & 0.53 \\
\hline SSR207 & 16 & 0.87 & 11 & 0.68 & 5 & 0.75 & 8 & 0.64 \\
\hline SSR230 & 13 & 0.83 & 11 & 0.83 & 4 & 0.72 & 5 & 0.65 \\
\hline SSR253 & 8 & 0.70 & 10 & 0.82 & 2 & 0.38 & 7 & 0.67 \\
\hline Total & 128 & & 134 & & 49 & & 100 & \\
\hline Mean & 9.14 & 0.65 & 9.57 & 0.73 & 3.5 & 0.59 & 7.14 & 0.66 \\
\hline SD & & 0.23 & & 0.21 & & 0.17 & & 0.18 \\
\hline $\mathrm{CV}$ & & 35.25 & & 29.18 & & 28.67 & & 27.41 \\
\hline
\end{tabular}

subspecies. The variation at microsatellite loci in all four subspecies is summarized in Table 4.

The total number of alleles detected across all microsatellite loci was 182 , with an overall average of 13 alleles per locus. Approximately $83 \%$ (151 alleles) of all alleles were observed in the wild accessions and only $62.6 \%$ (114 alleles) in the cultivated lentil. The number of alleles varied within the subspecies as well. The highest number of alleles was detected in L. culinaris subsp. orientalis (134); followed by L. culinaris subsp. culinaris (128) and L. culinaris subsp. odemensis (100). The number was lowest in L. culinaris subsp. tomentosus (49). With the exception of SSR202 and SSR28, all other lentil microsatellite markers showed relatively a high allelic diversity.

The values of genetic diversity for the microsatellite loci in the wild accessions ranged from 0.16 (for locus SSR28 in L. culinaris subsp. odemensis) to 0.93 (for the locus SSR66 in L. culinaris subsp. orientalis) with a mean of 0.66 , while in the cultivated lentil genetic diversity varied between 0.03 (for locus SSR28) and 0.87 (for locus SSR207) with a mean of 0.65 (Table 4 ). When gene diversity was compared subspecies wise, the highest mean gene diversity was also observed in L. culinaris subsp. orientalis $(0.73 \pm 0.21)$, followed by L. culinaris subsp. odemensis $(0.66 \pm 0.18)$ and L. culinaris subsp. culinaris $(0.65 \pm 0.23)$ (Table 4). Again, diversity was lowest in L. culinaris subsp. tomentosus (0.59 \pm 0.17 ) (Table 4).

\section{Genetic relationships}

The genetic relationships among the accessions were further studied using cluster analysis based on UPGMA. The dendrogram discriminated between all 109 lentil genotypes, which were grouped into two major clusters denoted as A and $\mathrm{B}$; these contained 51 and 58 accessions respectively, at a bootstrap value of $100 \%$ (Fig. 1). Cluster A could be subdivided into four sub-clusters denoted as A1, A2, A3, and A4 (Fig. 1). These clusters comprised 9, 12, 20, and 10 accessions, respectively. The results did not show clear separation of the accessions between L. culinaris subsp. orientalis, L. culinaris subsp. odemensis, and L. culinaris subsp. tomentosus. Among the 51 accessions, 48 were from wild lentil and three were from cultivated lentil (ILL632"Tur", ILL780"Syr", and ILL9918"ICARDA"). Only 11 of the 18 L. culinaris subsp. odemensis accessions clustered together in A3, while the remaining L. culinaris subsp. odemensis accessions were dispersed among the other clusters. Similarly, of the four accessions from subsp. tomentosus, only ILWL91 and ILWL 208 (from Turkey) were grouped together.

Cluster B contained 58 lentil accessions divided into four sub-clusters denoted as B1, B2, B3, and B4; these contained $12,16,11$, and 19 accessions respectively. Among the 58 Cluster-B accessions, 54 were from cultivated lentil and four were from wild L. culinaris subsp. orientalis (Fig. 1). 17 of 18 ICARDA breeding lines were clustered in B1, B3 and B4. These lines were clustered together with accessions from India, Pakistan, Syria, Turkey, Jordan, and Serbia. Of the 22 cultivated accessions from South Asia (India, Pakistan and Bangladesh), 19 (86\%) were grouped in B1 and B2.

Principal Co-ordinate Analysis (PCA), together with neighbor joining analysis, was conducted based on the accessions' country/origins (Fig. 2). The PCA indicated a strong population substructure with two well-separated clusters. The first cluster could be sub-divided into two smaller 


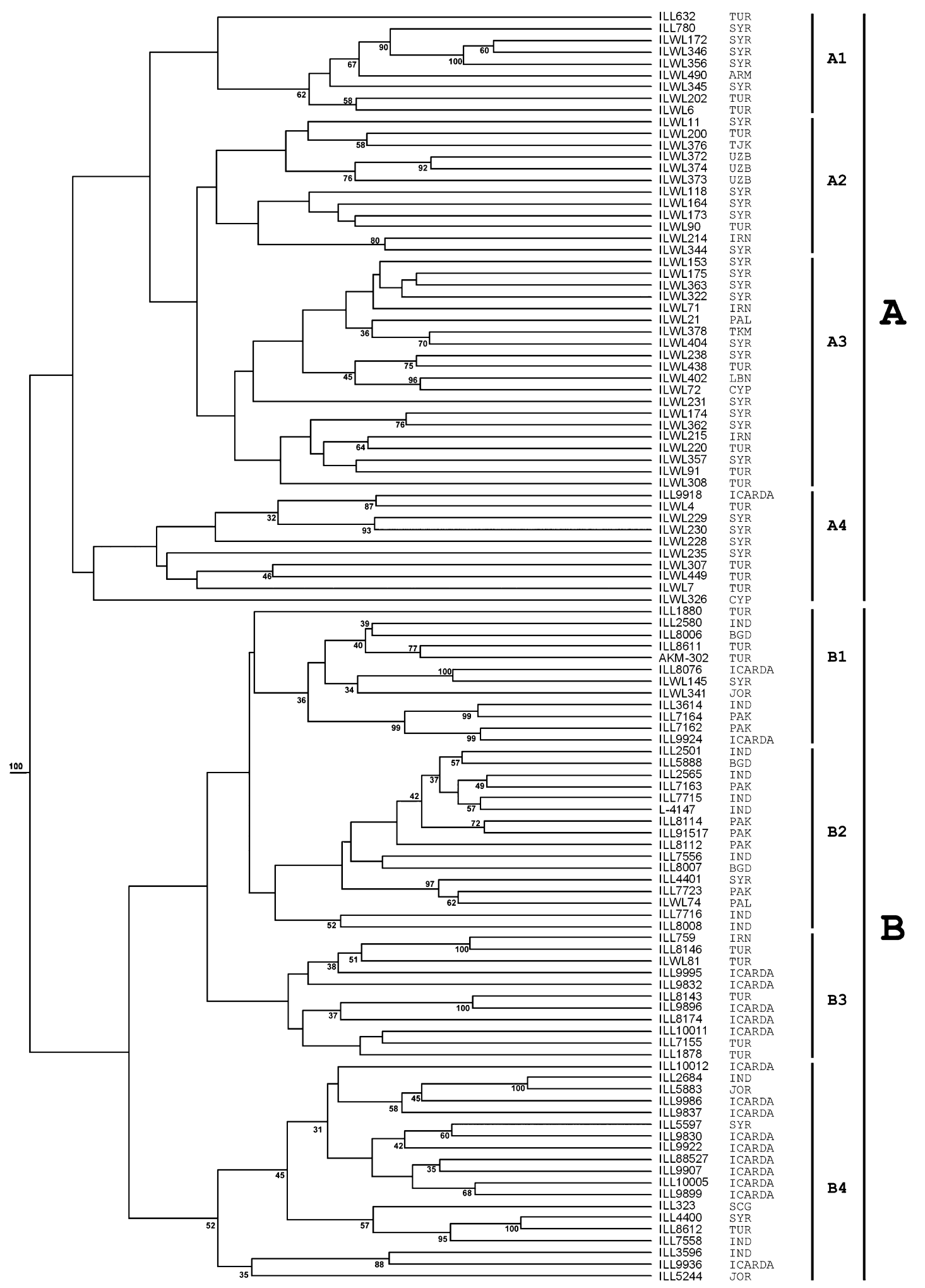

0.1

Fig. 1. Cluster analysis of wild and cultivated lentil accessions using 14 microsatellie markers. The groups are denoted on the right side as A or B, and the sub-groups as A1, A2, A3, A4, B1, B2, B3, and B4. The origins of 109 lentil accessions are listed closed to the genotype numbers. Bootstrap values of above $30 \%$ are indicated at the nodes. The abbreviations of the countries: Bangladesh (BGD), India (IND), Iran (IRN), Jordan (JOR), Pakistan (PAK), Syria (SYR), Turkey (TUR), Serbia \& Montenegro (SCG), Palestine (PAL), Armenia (ARM), Cyprus (CYP), Uzbekistan (UZB), Tajikistan (TJK), Turkmenistan (TKM), Lebanon (LBN). 
A

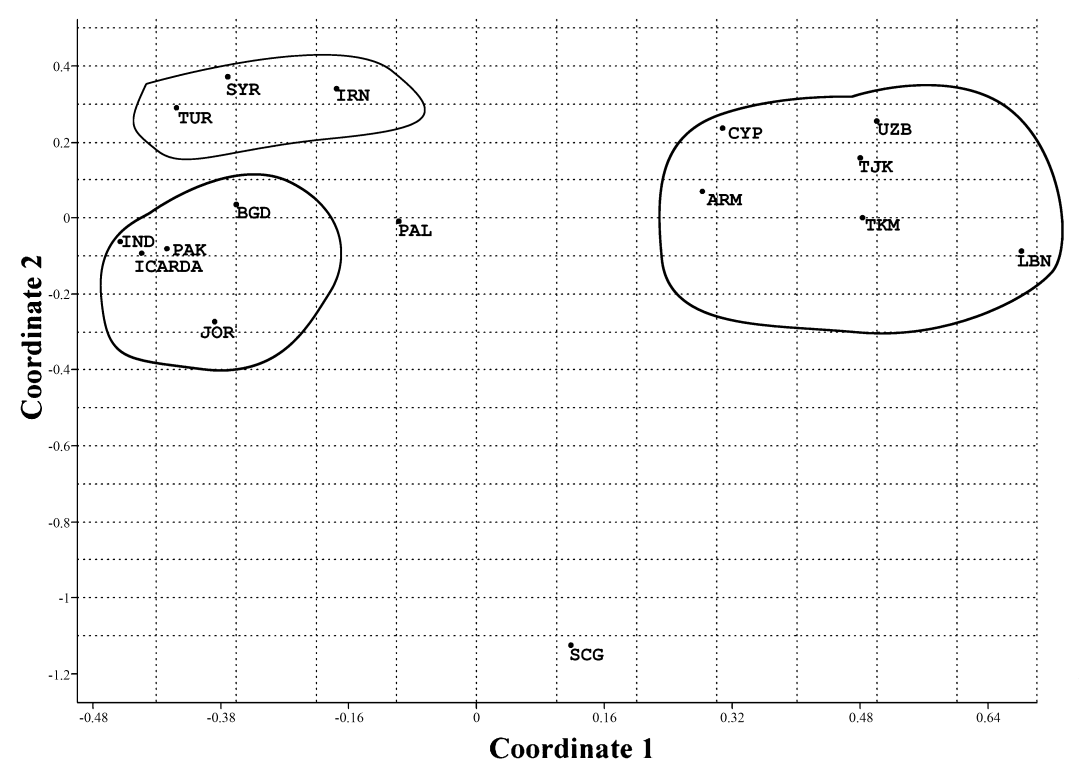

B

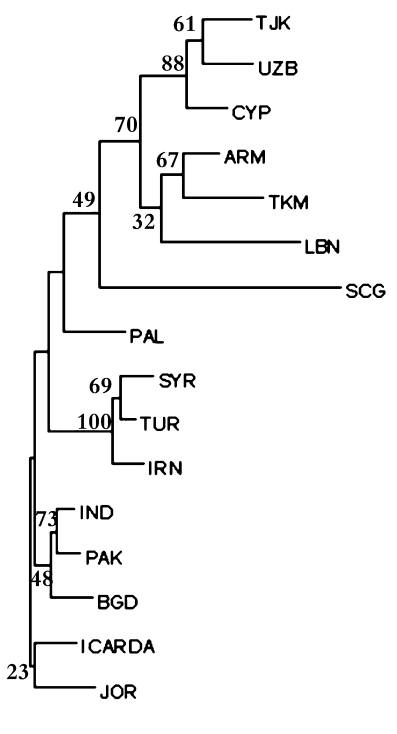

Fig. 2. Genetic relationships of lentil accessions originating from 15 countries of South Asia, Central Asia, and Fertile Crescent, as estimated by Nei's genetic distance (Nei 1973) based on the microsatellite data. (A): Principal co-ordinate analysis. (B): Neighbor joining cluster analysis. Bootstrap values are indicated at the nodes.

A

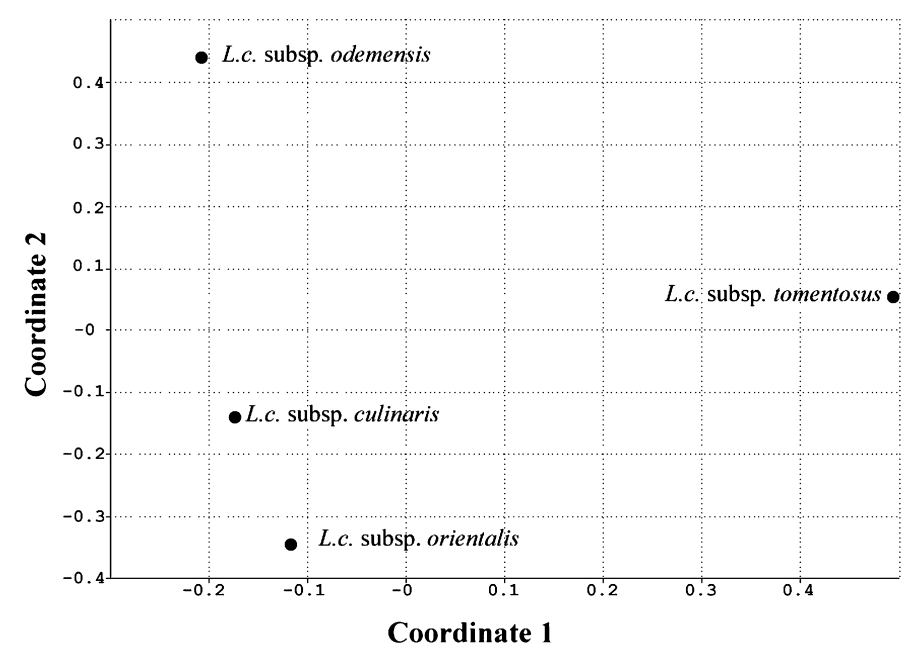

$\mathrm{B}$

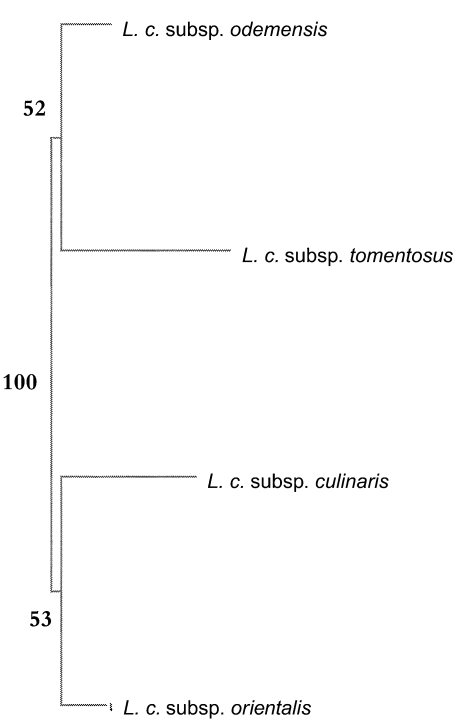

Fig. 3. Genetic relationships (as estimated by Nei' genetic distance) among the four Lens taxa based on 14 microsatellite markers analysis. (A) Principal co-ordinate analysis. (B) Neighbor joining cluster analysis. Bootstrap values are indicated at the nodes.

clusters separating Iran, Syria and Turkey from Jordan, India, Pakistan, Bangladesh and ICARDA breeding lines. The second cluster consisted of accessions from Armenia, Uzbekistan, Tajikistan, Turkmenistan, Cyprus, and Lebanon (Fig. 2).

The PCA of accessions based on the subspecies indicated that subspecies culinaris is more closely with subspecies orientalis than subspecies tomentosus and subspecies odemensis (Fig. 3).

\section{Discussion}

\section{Isolation of microsatellites}

The screening of 200,000 clones for $(\mathrm{GT})_{10},(\mathrm{GA})_{10}$, $(\mathrm{GC})_{10},(\mathrm{TA})_{10},(\mathrm{TAA})_{5}$ and $(\mathrm{GAA})_{8}$ identified 371 clones $(0.19 \%)$ likely to contain microsatellites. This is nearly 15 times less than the frequency achieved in wheat $(2.8 \%$; Röder et al. 1995) and about five times less than that achieved in chickpea (0.93\%; Hüttel et al. 1999). This difference between the frequency of clones likely to contain 
microsatellites in lentil and other species could be due to a property of lentil genome itself or due to various factors, such as the number and type of microsatellite motifs used for screening, insert size of the library, and the abundance of the microsatellites in the genome of each species.

Of the 371 lentil clones with putative microsatellite motifs, only 243 clones $(65.5 \%)$ were used for sequencing. The remaining clones $(34.5 \%)$ were rejected based on insert size analysis, because of the presence of more than one insert, or the possibility that they represented duplicate clones. After sequencing, $173(71.2 \%)$ clones possessed microsatellites, and the remaining 70 clones $(28.8 \%)$ were 'lost' because of the absence of a microsatellite. In several previous studies, inevitably some clones were sequenced that did not contain a microsatellite; in those studies, the proportions of not containing a microsatellite were, for example, $42 \%$ in Anisantha sterilis (Green et al. 2000), 33\% in rapeseed (Kresovich et al. 1995), and 23\% in olive (Carriero et al. 2002).

More of the repeats in lentil were dinucleotide rather than trinucleotide repeats. This finding agrees with earlier reports that dinucleotide repeats are relatively abundant in many plant species including wheat (Wang et al. 1994, Ma et al. 1996, Bryan et al. 1997). Our results indicated CA/GT repeats might be a major type of microsatellite in the lentil genome. The CA/GT repeat is one of the most frequently occurring microsatellites in humans and many other mammals (Toth et al. 2000) and also in some plant libraries, such as wheat (Varshney et al. 2000) and Pinus radiata (Smith and Devey 1994); however, that repeat is less frequent in many other plants (Lagercrantz et al. 1993).

\section{Variation at microsatellite loci in cultivated and wild lentil species}

We used the PCR conditions standardized for cultivated lentils successfully to amplify microsatellites in the wild relatives. Amplification with the same set of primers should be possible only if these species are closely related. Several studies have used homologous microsatellite flanking sequences developed in one species for diversity analysis in closely related species (Udupa et al. 1999, Choumane et al. 2000, Brondani et al. 2003, Adonina et al. 2005).

By assessing a worldwide collection of four subspecies of the genus Lens for a set of 14 microsatellite loci, we revealed a large amount of genetic variability among and within the subspecies. This result is not surprising considering the sampling scale and the class of markers we used. Microsatellite markers are known to show high mutation rates (Udupa and Baum 2001), and are thus expected to reveal a high degree of polymorphism (Udupa et al. 1999). We did, however, find large variation among microsatellite marker loci for both gene diversity and allelic numbers, with the exception of two loci (SSR28 and SSR202) which gave less than four alleles for the species tested.

\section{Genetic relationships}

The cluster analysis of 109 accessions indicated two major clusters at a bootstrap value of $100 \%$. About $92 \%$ of wild accessions were clustered together in cluster A, and were clearly separated from the cultivated lentil. Similarly, $93 \%$ of cultivated lentil accessions clustered in the major cluster B. Four of 30 accessions (13.3\%) from L. culinaris subsp. orientalis clustered with the cultivated germplasm, while none of the other wild subspecies were clustered with the cultivated germplasm. The clustering of some of the wild and cultivated accessions could be due to the occurrence of intermediate morphological forms particularly in the areas of the Fertile Crescent, resulting from out-crossing between wild and cultivated forms (gene introgression), as previously observed by Ferguson et al. (1998b).

L. culinaris subsp. tomentosus and L. culinaris subsp. odemensis are genetically distant from cultivated lentil, and are therefore unlikely to be the progenitors of cultivated lentil. The high degree of genetic differentiation at microsatellite loci and their hitch-hiking to the adaptive traits could be responsible for this level of the differences between wild and cultivated accessions. Genetic drift due to genetic bottlenecks and fluctuations in the population sizes of cultivated and wild species might have also contributed to the overall genetic differentiation in wild and cultivated lentil populations. A similar strong differentiation between cultivated and wild relatives has been observed in pigeonpea and pearl millet (Mariac et al. 2006, Yang et al. 2006).

High genetic diversity was observed within the accessions of $L$. culinaris subsp. orientalis, of which about $80 \%$ are from the Fertile Crescent (the north and south of Syria, Turkey, Iran, Jordan, Lebanon, Cyprus, and Palestine). Ferguson and Robertson (1996) found that L. culinaris subsp. orientalis possessed the high diversity based on morphological characters compared to isozymes markers. Ferguson et al. (1998a) also reported high genetic diversity (based on RAPD analysis) in L. culinaris subsp. orientalis accessions from Jordan, Palestine, and southern Syria, with slightly lower diversity in those accessions from northwest Syria and southeast Turkey.

The accessions of L. culinaris subsp. odemensis in this study collected from Syria, Turkey, and Palestine were distributed widely within cluster $\mathrm{A}$, indicating high genetic diversity at microsatellite loci. Previously, Ferguson et al. (1998a) reported high genetic diversity for this species only in Sweida province of Southern Syria.

Out of the 22 accessions originating from South Asia (India, Pakistan and Bangladesh), 14 (64\%) were clustered in sub-cluster B2, while the other accessions were distributed across the B1 and B4 clusters. The PCA based on geographic origin also showed that accessions from South Asian countries clustered together, providing molecular evidence for the clustering based on phenotypic variation observed previously for the South Asian accessions (Rahman and Sarker 1993, Erskine et al. 1998).

Although the accessions from Syria, Turkey, and Iran showed high genetic diversity, they were found to be closely related according to their origins (Fig. 2). These countries 
are a part of the Fertile Crescent, where lentil was first domesticated. A previous study that mapped the geographical distribution of genetic variation in lentil from Syria and Turkey using RAPD markers also revealed areas of high and unique diversity (Ferguson et al. 1998a).

Our grouping of accessions based on microsatellite variation confirmed that the orientalis subspecies is closer to the culinaris subspecies than to the tomentosus and odemensis subspecies and did not show whether tomentosus subspecies is closer to the culinaris subspecies. However, Ferguson et al. (2000) re-classified Lens taxa, indicating that the tomentosus subspecies is closer to the culinaris subspecies than to the odemensis subspecies.

To meet the need for co-dominant markers in lentil, we identified additional microsatellite primers, and used them for the first time to study the genetic diversity within wild and cultivated lentils. The results indicated strong differentiation between wild and cultivated lentils, which were clearly separated by the analyses into two gene pools. Our results show a better resolution in classification of the Lens taxa by using microsatellite markers.

\section{Acknowledgements}

The research of the ICARDA scientists was supported by grants from the German Federal Ministry of Economic Cooperation and Development (BMZ, Bonn, Germany), the CGIAR's Generation Challenge Program, and the Global Center of Excellence for Dryland Science, Tottori, Japan.

\section{Literature Cited}

Abe,J., D.H.Xu, Y.Suzuki, A.Kanazawa and Y.Shimamoto (2003) Soybean germplasm pools in Asia revealed by nuclear SSRs. Theor. Appl. Genet. 106: 445-453.

Abo-elwafa,A., K. Murai and T.Shimada (1995) Intra- and interspecific variations in Lens revealed by RAPD markers. Theor. Appl. Genet. 90: 335-340.

Adonina,I.G., E.A.Salina, E.G.Pestsova and M.S.Röder (2005) Transferability of wheat microsatellites to diploid Aegilops species and determination of chromosomal localizations of microsatellites in the S genome. Genome 48: 959-970.

Bahl,P.N., S.Lal and B.M.Sharma (1993) An overview of the production and problems in southeast Asia. In: Erskine, W. and M.C. Saxena (eds.) Lentil in South Asia. Proceedings of the seminar on lentils in South Asia, ICARDA, Aleppo, Syria, pp. 1-10.

Brondani,C., P.H.Rangel, T.C.Borba and R.P.Brondani (2003) Transferability of microsatellite and sequence tagged site markers in Oryza species. Hereditas 138: 187-192.

Bryan, G.J., A.J.Collins, P. Stephenson, A. Orry, J.B. Smith and M.D.Gale (1997) Isolation and characterization of microsatellites from hexaploid bread wheat. Theor. Appl. Genet. 94: 557-563.

Carriero,F., G.Fontanazza, F.Cellini and G.Giorio (2002) Identification of simple sequence repeats (SSRs) in olive (Olea europaea L.). Theor. Appl. Genet. 104: 301-307.

Choumane,W., P.Winter, F.Weigand and G.Kahl (2000) Conservation and variability of sequence-tagged microsatellite sites (STMSs) from chickpea (Cicer arietinum L.) within the genus Cicer. Theor.
Appl. Genet. 101: 269-278.

Collard, B.C.Y., R.A. Grams， W.D. Bovill， C.D. Percy， R. Jolley, A.Lehmensiek, G. Wildermuth and M.W. Sutherland (2005) Development of molecular markers for crown rot resistance in wheat: mapping of QTL for seedling resistance in a "2-49" $\mathrm{X}$ "Janz" population. Plant Breeding 124: 532-537.

Davis,J.C. (1986) Statistics and Data Analysis in Geology. John Wiley \& Sons, New York.

Duke,J.A. (1981) Handbook of Legumes of World Economic Importance. Plenum Press, New York, pp. 52-57.

Erskine, W., S.Chandra, M.Chaudhry, I.A.Malik, A.Sarker, B.Sharma, M.Tufail and M.C.Tyagi (1998) A bottleneck in lentil: Widening its genetic base in South Asia. Euphytica 101: 207-211.

FAOSTAT database (2008) http://faostat.fao.org/

Ferguson,M.E. and L.D. Robertson (1996) Genetic diversity and taxonomic relationships within the genus Lens as revealed by allozyme polymorphism. Euphytica 91: 163-172.

Ferguson, M.E., B.V.Ford-Lloyd， L.D. Robertson， N. Maxted and H.J.Newbury (1998a) Mapping the geographical distribution of genetic variation in the genus Lens for the enhanced conservation of plant genetic diversity. Mol. Ecol. 7: 1743-1755.

Ferguson, M.E., H.J.Newbury, N. Maxted, B.V. Ford-Lloyd and L.D.Robertson (1998b) Population genetic structure in Lens taxa revealed by isozyme and RAPD analysis. Genetic Resources and Crop Evolution. 45: 549-559.

Ferguson,M.E., N.Maxted, H.V.Slangeren and L.D.Robertson (2000) A reassessment of the taxonomy of Lens Mill. (Leguminosae, Papilionoidae, Vicieae). Bot. J. Lin. Soc. 133: 41-59.

Green, J.M., K.J.Edwards, S.L. Usher, J.H. Barker, E.J. Marshall, R.J.Froud-Williams and A.Karp (2000) Microsatellites for Barren Brome (Anisantha sterilis). Mol. Ecol. 9: 2195-2197.

Hammer,Ø., D.A.T.Harper and P.D.Ryan (2001) PAST: Palaeontological Statistics software package for education and data analysis. Palaeontologia Electronica 4: 9.

Hamwieh,A., S.M.Udupa, W.Choumane, A.Sarker, F.Dreyer, C.Jung and M.Baum (2005) A genetic linkage map of Lens spp. based on microsatellite and AFLP markers and the localization of fusarium vascular wilt resistance. Theor. Appl. Genet. 110: 669-677.

Havey,M.J. and F.J.Muehlbauer (1989) Variability for restriction fragment lengths and phylogenies in lentils. Theor. Appl. Genet. 77: 839-843.

Hoffman,D.L., D.E.Soltis, F.J.Muehlbauer and G.Ladizinsky (1986) Isozyme polymorphism in Lens (Leguminosae). Syst. Bot. 11: 392-402.

Hüttel, B., P. Winter, K. Weising, W.Choumane, F. Weigand and G.Kahl (1999) Sequence-tagged microsatellite site markers for chickpea (Cicer arietinum L.). Genome 42: 210-217.

Kresovich,S., A.K.Szewc-McFadden, S.M.Bliek and J.R.McFerson (1995) Abundance and characterization of simple-sequence repeats (SSRs) isolated from a size-fractionated genomic library of Brassica napus L. (rapeseed). Theor. Appl. Genet. 91: 206-211.

Ladizinsky,D., D.Braun and F.J.Muehlbauer (1984) The biological species of the genus Lens. Bot. Gaz. 145: 235-261.

Lagercrantz,U., H.Ellegren and L.Andersson (1993) The abundance of various polymorphic microsatellite motifs differs between plants and vertebrates. Nucl. Acid Res. 21: 1111-1115.

Liu,K. and S.V.Muse (2005) PowerMarker: Integrated analysis environment for genetic marker data. Bioinformatics 21: 2128-2129.

Ma,Z.Q., M.Röder and M.E.Sorrells (1996) Frequencies and sequence characteristics of di-, tri- and tetra-nucleotide microsatellites in wheat. Genome 39: 123-130. 
Mariac, C., V.Luong, I.Kapran, A.Mamadou, F.Sagnard, M.Deu, J.Chantereau, B.Gérard, J.Ndjeunga, G.Bezancon, J.Pham and Y.Vigouroux (2006) Diversity of wild and cultivated pearl millet accessions (Pennisetum glaucum L.) in Niger assessed by microsatellite markers. Theor. Appl. Genet. 114: 49-58.

Nei,M. (1973) Analysis of gene diversity in subdivided populations. Proc. Natl. Acad. Sci. USA 70: 3321-3323.

Powell,W., G.C.Mackray and J.Provan (1996) Polymorphism revealed by simple sequence repeats. Trends in Plant Science 1:215222.

Rahman,M.M. and A.Sarker (1993) Genetic resources and breeding of lentil in Bangladesh. Lentils in South Asia. Proceedings of the Seminar on Lentils in South Asia, 11-15 March 1991. vi+236pp.

Röder,M.S., J.Plaschke, S.U.König, A.Börner, M.E.Sorrells, S.D. Tanksley and M.W.Ganal (1995) Abundance, variability and chromosomal location of microsatellites in wheat. Theor. Appl. Genet. 246: 327-333.

Rogers, S.O. and A.J.Bendich (1985) Extraction of DNA from milligram amounts of fresh, herbarium and mummified plant tissues. Plant Mol. Biol. 5: 69-76.

Sarker,A. and W.Erskine (2006) Recent progress in the ancient lentil. Journal of Agricultural Science 100: 19-29.

Sharma,S.K., I.K.Dawson and R.Waugh (1995) Relationship between cultivated and wild lentils revealed by RAPD analysis. Theor. Appl. Genet. 91: 647-654.

Sharma,S.K., M.R.Knox and T.H.N.Ellis (1996) AFLP analysis of the diversity and phylogeny of Lens and its comparison with RAPD analysis. Theor. Appl. Genet. 93: 751-758.

Sibly, R.M., J.C. Whittaker and M. Talbot (2001) A maximumlikelihood approach to fitting equilibrium models of microsatellite evolution. Mol. Biol. Evol. 18: 413-417.
Smith,D. and M.E.Devey (1994) Occurrence and inheritance of microsatellites in Pinus radiata. Genome 37: 977-983.

Struss, D. and J.Plieske (1998) The use of microsatellite markers for detection of genetic diversity in barley populations. Theor. Appl. Genet. 97: 308-315.

Toth,G., Z.Gaspari and J.Jurka (2000) Microsatellites in different eukaryotic genomes: survey and analysis. Genome Res. 10: 967-981.

Udupa,S.M., L.D.Robertson, F.Weigand, M.Baum and G.Kahl (1999) Allelic variation at (TAA $)_{n}$ microsatellite loci in a world collection of chickpea (Cicer arietinum L.) germplasm. Mol. Gen. Genet. 261: 354-363.

Udupa,S.M. and M.Baum (2001) High mutation rate and mutational bias at (TAA $)_{\mathrm{n}}$ microsatellite loci in chickpea (Cicer arietinum L.). Mol. Genet. Genomics 265: 1097-103.

vanOss,H., Y.Aron and G.Ladizinsky (1997) Chloroplast DNA variation and evolution in the genus Lens Mill. Theor. Appl. Genet. 94: $452-457$.

Varshney, R.K., A. Kumar， H.S. Balyan, J.K. Roy, M. Prasad and P.K.Gupta (2000) Characterization of microsatellites and development of chromosome specific STMS markers in bread wheat. Plant Mol. Biol. Rep. 18: 5-16.

Wang,Z., J.L.Weber, G.Zhong and S.D.Tanksley (1994) Survey of plant short tandem DNA repeats. Theor. Appl. Genet. 88: 1-6.

Weber,J.L. (1990) Informativeness of human $(\mathrm{dC}-\mathrm{dA})_{\mathrm{n}}(\mathrm{dG}-\mathrm{dT})_{\mathrm{n}}$ polymorphisms. Genomics 7: 524-530.

Winter,P. and G.Kahl (1995) Molecular marker technologies for crop improvement. World J. Microbiol. Biotechnol. 11: 449-460.

Yang, S., W.Pang, G.Ash, J.Harper, J.Carling, P.Wenzl, E.Huttner, X.Zong and A.Kilian (2006) Low level of genetic diversity in cultivated Pigeonpea compared to its wild relatives is revealed by diversity arrays technology. Theor. Appl. Genet. 113: 585-595. 